\title{
Hidden Sugar and its Bitter Obstacles for the Wellbeing of Consumers
}

\author{
Ai Nhan Ngo \\ The University of Texas Rio Grande Valley
}

Follow this and additional works at: https://digitalcommons.uri.edu/mgdr

Part of the Business Law, Public Responsibility, and Ethics Commons, Dietetics and Clinical Nutrition Commons, Health and Physical Education Commons, International Business Commons, Marketing Commons, and the Public Affairs, Public Policy and Public Administration Commons

\section{Recommended Citation}

Ngo, Ai Nhan (2020) "Hidden Sugar and its Bitter Obstacles for the Wellbeing of Consumers," Markets, Globalization \& Development Review. Vol. 5: No. 2, Article 2.

DOI: 10.23860/MGDR-2020-05-02-02

Available at: https://digitalcommons.uri.edu/mgdr/vol5/iss2/2

This Article is brought to you for free and open access by DigitalCommons@URI. It has been accepted for inclusion in Markets, Globalization \& Development Review by an authorized editor of DigitalCommons@URI. For more information, please contact digitalcommons-group@uri.edu. 


\section{Markets, Globalization \& Development Review}
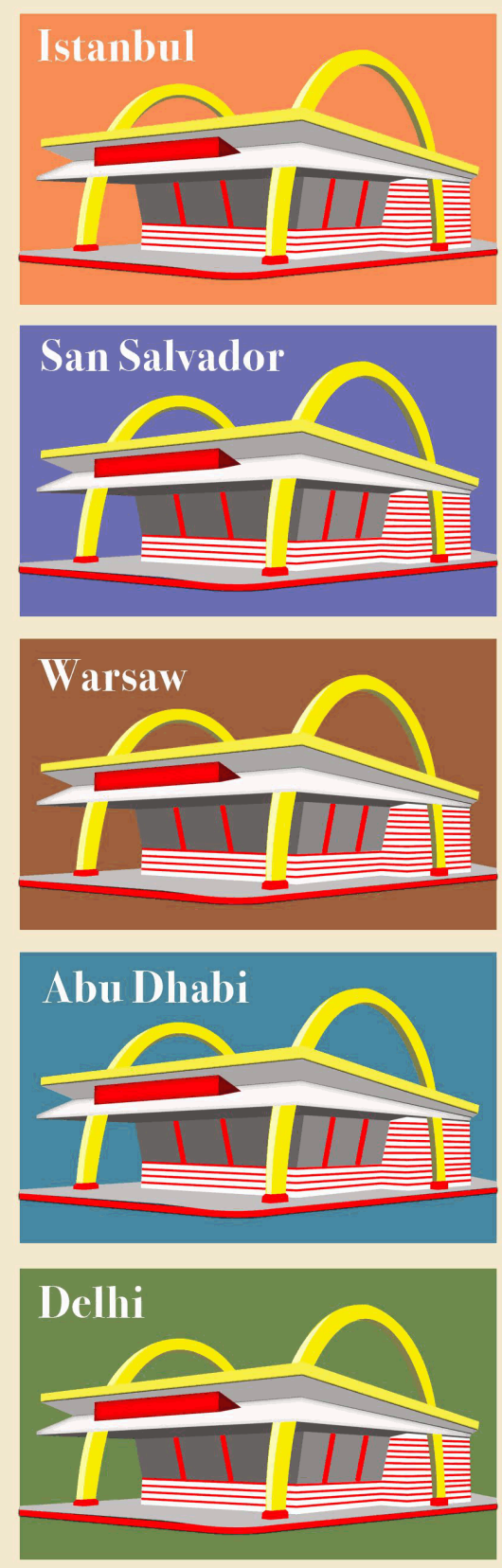
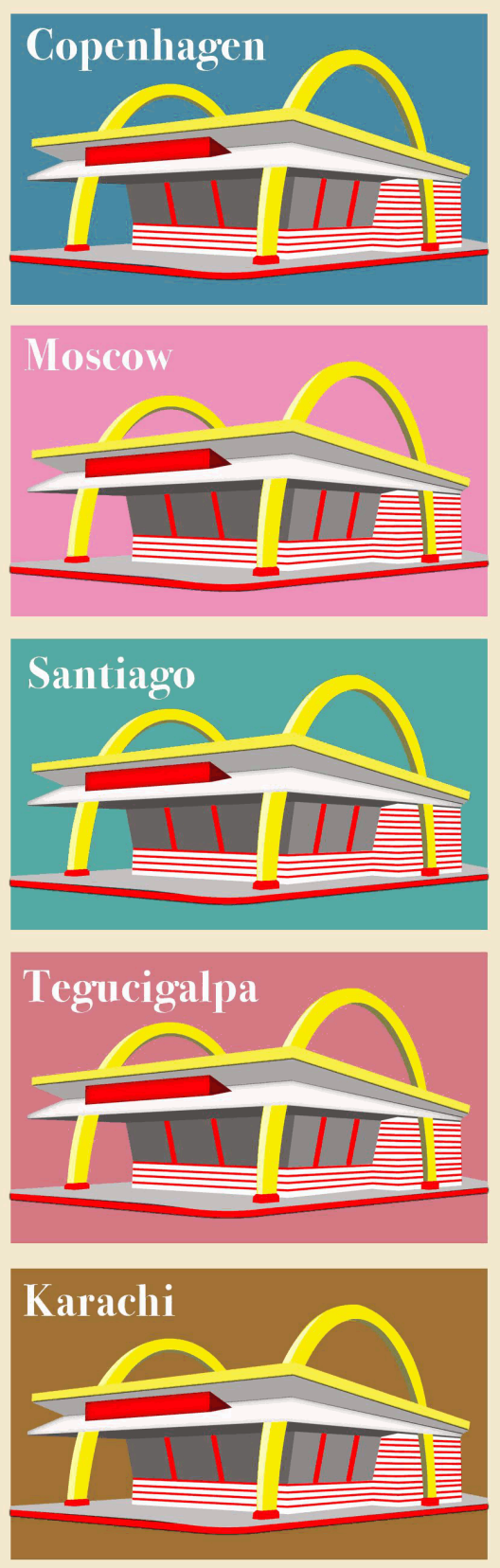
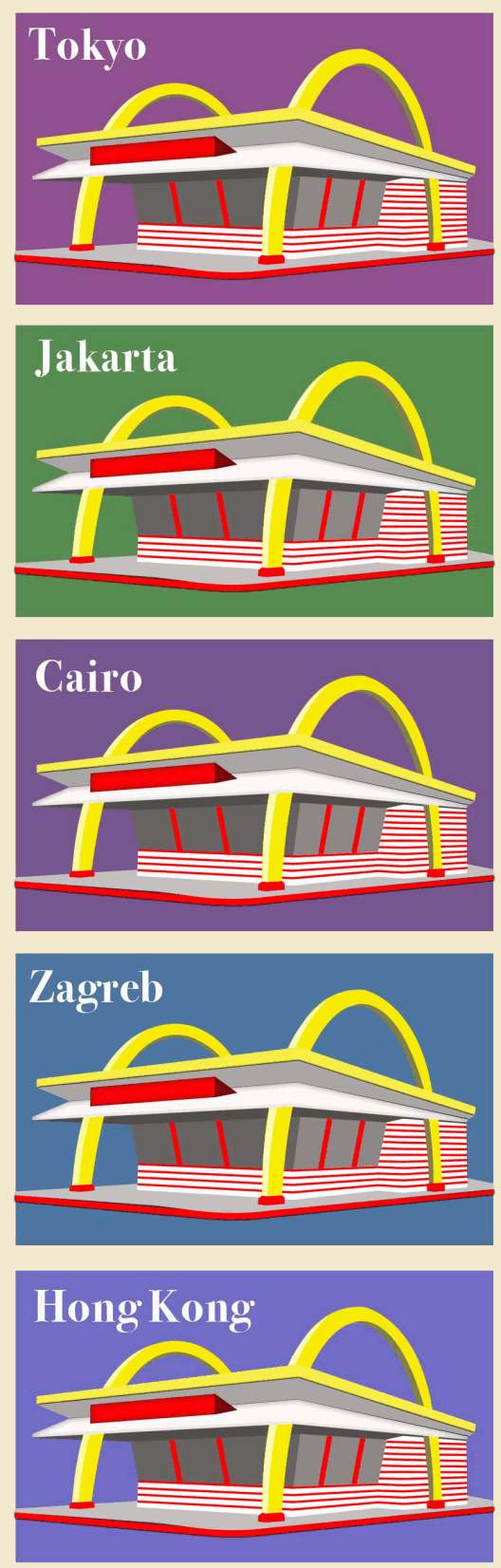

This article is available in Markets, Globalization \& Development Review: https://digitalcommons.uri.edu/mgdr/vol5/ 


\section{Hidden Sugar and its Bitter Obstacles for the Wellbeing of Consumers}

\section{Introduction}

During human evolution, hominids diversified their diet and split from hominoids between 4.4 and 2.3 million years ago but kept a preference for sweet fruits which allowed them to have enough energy and good nutrition for survival during their migrations (Breslin 2013). As they do today, human beings have a strong attraction to sweetness. Sweetness, while important for energy supply, can also be addictive. Avena, Rada and Hoebel (2008) indicated that sugar dependence can be developed in rats under several conditions, and the translation of their findings to human eating disorders and obesity is supported by literature. Sugar addiction has been concealed from consumers as shown in the 2013 episode titled 'The Secrets of Sugar' of the series The Fifth Estate from CBS News. More importantly, the documentary indicated the relationship between sugar and other diseases such as obesity, type II diabetes, Alzheimer's, heart disease and cancer.

This television episode and others have also revealed that the Sugar Association, formerly named the Sugar Research Foundation (SRF), lobbied Harvard scientists to identify fat (and not sugar) as a causal risk factor of heart disease. Later, Kearns, Schmidt and Glantz (2016) conducted a historical analysis of 346 documents regarding the SRF's sponsorship of research from 1959 to 1971 and other SRF materials from WorldCat Library. They suggested that "the industry may have a long history of influencing federal policy" (p. 1683). Moreover, the CBS News film showed that there was close cooperation between the sugar industry, the food industry, and policymakers, creating a strong network that put more sugar on consumers' tables, hid the extra sugar in products they ate, and negatively affected public health. Gearhardt, Roberts and Ashe (2013) point out that "the negative impact of any addictive potential associated with these (unnaturally high-sugar) foods is enhanced by the cheapness, accessibility, and heavy marketing of these products, thus increasing the public health burden" (p. 47). Obviously, marketing was blamed; however, the addition of sugar to foods that creates addictive sugar consumption is a sophisticated operation that requires further exploration, and remains a challenge to society. Thus, it is crucial to identify the obstacles that prevent consumers from lowering their sugar consumption as well as finding solutions for removing those obstacles. 
High sugar consumption has been explored by such disparate fields as anthropology (e.g., the classic book 'Sweetness and Power', Mintz 1986), medicine, biology, nutrition, behavior, neuroscience, and law. The subject has been covered by the news media. In the marketing field, however, the topic is under-addressed. Using literature from those related fields, this paper first discusses the effects of high sugar intake on human health. Next, the obstacles created by industries, policymakers, policy influencers, and consumers themselves - that make it difficult for consumers to lower their sugar intake - are presented. Finally, several recommendations for reducing the consumption of addictive added sugars are made as stepping stones toward future work.

\section{How Sugar Affects Human Health}

Cantley (2014), an important contributor to human understanding about cancer metabolism, explained the different effects of fructose and glucose on the human body and how an addiction to sweetness is created. When a person eats sucrose (table sugar), which is a two-molecule linked sugar consisting of fructose and glucose, the two molecules will be broken up when it gets in the human body. The liver differentiates the molecules in such a way that half of them are glucose, which supplies energy to the brain and muscles, and half are fructose, which becomes fat. The brain takes only the glucose, which is only half of the amount of sweetness that the brain tastes from sugar intake. Thus, it wants more glucose, meaning more sugar intake. "The more sugar you eat, the more it wants you to eat" (Cantley 2014, p.3). This loop of sugar craving is the addiction to sweet foods. Cantley also explains that humans in ancient time needed fructose to store fat for winters when food became scarce; however, modern consumers do not have that need. Having fructose in food products does not contribute to consumer's wellbeing; instead, it increases fat storage and heightens the risk of obesity.

Body metabolism is complex, making it difficult to establish a causal relationship between high sugar intake and the onset of various diseases. Goncalves, Hopkins and Cantley (2019) found, however, that there are indirect and direct causal relationships between dietary sugar and certain tumors in colorectal and endometrial cancers. Moreover, a special report by Lauby-Secretan et al. (2016) in the New England Journal of Medicine concerning the association between body fat and cancer indicated that the risk of having several different cancers are reduced with the absence of excess body fat. Therefore, high sugar intake may directly or indirectly increase consumers' risk of getting several types of these aggressive diseases. 
Beside cancers, consumption of sugar sweetened beverages is found to have an association with Type II diabetes risk (Imamura et al. 2015; Malik et al. 2010) and may increase cardiovascular risk without the involvement of obesity (Malik et al. 2010). Added sugar consumption is also significantly related to cardiovascular mortality risk in US adults (Yang et al. 2014). A meta-analysis research on the relationship between sugar consumption and dental caries/cavities risk showed that a control on sugar consumption help prevent tooth decay (Burt and Pai 2001). The positive relationship between sugar consumption and tooth decay is found in young consumers (six to18 year-olds) with even low sugar intake, despite their use of fluoride (Peres et al. 2016). Research also focuses on the relationship between high sugar intake and mental health. Yu et al. (2016) found an association between sugar intake from sugary beverage consumption and ADHD in Taiwanese children; however, causality between them requires further research. In adult consumers, Reis et al. (2020) summarized the linkage between sugar and depression from extant literature. The outline of the linkages indicated neuroinflammation as an important risk factor that mediates the sugar/depression relationship. This relationship also, however, requires further empirical investigation.

All this scientific evidence supports the finding that sugar may cause serious consequences to consumers' wellbeing; however, it seems difficult for consumers to give up this addictive sweetener. The difficulty comes from both intrinsic and extrinsic factors. Several obstacles prevent consumers from lowering their sugar consumption, and we turn to these next.

\section{Obstacles from Policymakers}

\section{Obstacles from Its Own Names}

The definition of sugars, added sugars, and free sugars can be complicated. On the one hand, in the Nutrition and Supplement Facts Labels: Questions and Answers Related to the Compliance Date, Added Sugars, and Declaration of Quantitative Amounts of Vitamins and Minerals: Guidance for Industry, the Food and Drug Administration (FDA) defined added sugars as follows:

Sugars that are either added during the processing of foods, or are packaged as such (e.g., a bag of sugar). Added sugars include sugars (free, mono- and disaccharides), sugars from syrups and honey, and sugars from concentrated fruit or vegetable juices that are in excess of what would be expected from the same volume of 100 percent fruit or vegetable juice of the same type (2018, revised 2019, p.7). 
According to this definition, added sugars are defined as the extra amount of sugar existing in a product, which is in excess of the natural amount of sugar contained in the real fruit or juice. On the other hand, the term free sugar is elaborated by the World Health Organization (WHO):

Free sugars include monosaccharides and disaccharides added to foods and beverages by the manufacturer, cook or consumer, and sugars naturally present in honey, syrups, fruit juices and fruit juice concentrates (World Health Organization 2015, p.4).

Comparing the terms and definitions, free sugars are added sugars. The confusing and confounding terms regarding sugar, however, do not stop here. The various names of sugar listed in ingredient lists are much more complex. The Sugar Association website (n.d.) provided a list of only 22 examples of the FDA's definition of added sugars. In contrast, and going further, SugarScience (n.d.), a group of health scientists from the University of California San Francisco, provides a more complete list of sugar names on food labels with 61 different names. This paper features a quick analysis by excluding all the names containing easy-to-recognizeas-sugar words such as sugar, syrup, glucose, sucrose, maltose, fructose, sweet, or sweetener. Even excluding these, there are still 20 hidden names of sugar including agave nectar, barley malt, cane juice, cane juice crystals, caramel, dehydrated cane juice, dextrin, dextrose, evaporated cane juice, fruit juice, fruit juice concentrate, honey, maltodextrin, maltol, mannose, molasses, muscovado, panocha, saccharose, and treacle. Some hidden names might be perceived as a high quality and healthy alternative for sugar such as honey, fruit juice, cane juice, caramel, and agave nectar. When consumers accidentally get lost in this maze, it becomes more difficult to protect themselves from overconsuming sugar.

\section{Efforts to Lift Some Obstacles}

Although the FDA provided several examples regarding the calculation of the amount of added sugars, it also stated that:

It is up to the manufacturer to determine which ingredients provide sugars that meet the definition of added sugars. Manufacturers are in the best position, given their knowledge of their supply chain and production practices, to determine what method is most suitable for determining the added sugars declaration. We do not have a specific formula or calculator that must be used for determining the amount of added sugars in a finished food product (Food and Drug Administration 2018, revised 2019, p.8). 
With this statement, the FDA gives the manufacturers the right to define their own measurement formula, which affects the amount of added sugars announced on their nutrition labels. According to the FDA, starting from January 1, 2020, manufacturers must follow a compliance procedure to update their Nutrition Facts as shown in Figure 1.

With the new label, the amount of added sugars in a product is declared in a clearer way. Besides, the old label did not include the "\% Daily Value of sugars" information. The definition of the \% Daily Value is shown at the bottom of the label on the right. Based on the calculation that $10 \mathrm{~g}$ of added sugars account for $20 \%$ Daily Value, the label suggests a sugar consumption of $50 \mathrm{~g} /$ person/day, which is almost two times the desirable suggested amount from the WHO or the American Heart Association (AHA). The WHO (2015) strongly recommends that free sugar intake should be less than $10 \%$ of total energy intake. WHO also calls for limiting free sugar intake to less than $5 \%$ of total energy intake, equivalent to less than $10 \mathrm{~kg} /$ person/year or $27.4 \mathrm{gram} /$ person/day. The American Heart Association (2018), or AHA, also makes recommendations with more details about daily added-sugar intake. The limit for men is no more than 9 teaspoon/36 grams/150 calories and the limit for women is no more than 6 teaspoon/25 grams/100 calories.

To illustrate the WHO and AHA recommendations, a 12-ounce can of Coke contains $39 \mathrm{~g}$ of added sugars. It is the equivalent to $78 \%$ of daily sugar consumption according to the FDA, $142 \%$ according to the desirable limitation by the WHO, $108 \%$ and $156 \%$ for men and women respectively according to the AHA. On a daily basis, thus, a single can of Coke causes overconsumption according to the WHO and the AHA. It is unknown if consumers have wide access to the various recommendations. It is also unknown as to why the FDA prefers the upper limit of sugar consumption to the lower limit as recommended by the AHA.

To evaluate the effect of the new nutrition facts label, Neuhofer et al. (2020) used an eye-tracking device to determine if the label can help to reduce sugar-sweetened beverage consumption. It was found that the revised label drew more attention but did not strongly affect consumers' choices in terms of healthy practices. The ineffectiveness of the FDArequired new label can be an obstacle that prevents consumers from reducing their sugar intake. Of note, this label is placed on the back or side of a product where only about one third of consumers take advantage of the information (Derby and Levy 2001). 


\section{Figure 1: Side-by-side Comparison of Original and New Nutrition Labels}

\section{SIDE-BY-SIDE COMPARISON}

\section{Original Label}

\begin{tabular}{|c|c|c|c|}
\hline Amount Per Servi & & & \\
\hline Calories 230 & Cal & pries fron & Fat 72 \\
\hline & & $\%$ Dail & Value* \\
\hline Total Fat $8 \mathrm{~g}$ & & & $12 \%$ \\
\hline Saturated Fa & & & $\mathbf{5 \%}$ \\
\hline Trans Fat Og & & & \\
\hline Cholesterol 0 & & & $\mathbf{0} \%$ \\
\hline Sodium 160m & & & $7 \%$ \\
\hline Total Carboh & drate 37 & & $12 \%$ \\
\hline Dietary Fiber & & & $16 \%$ \\
\hline Sugars 12g & & & \\
\hline Protein $3 g$ & & & \\
\hline Vitamin A & & & $10 \%$ \\
\hline Vitamin C & & & $8 \%$ \\
\hline Calcium & & & $20 \%$ \\
\hline Iron & & & $45 \%$ \\
\hline $\begin{array}{l}\text { "Percent Daily Value } \\
\text { Your daily value ma }\end{array}$ & $\begin{array}{l}\text { are based o } \\
\text { be higher or }\end{array}$ & $\begin{array}{l}\text { a } 2,000 \mathrm{ca} \\
\text { ower depen }\end{array}$ & $\begin{array}{l}\text { orie diet. } \\
\text { ing on }\end{array}$ \\
\hline your calorie needs. & Calories: & 2,000 & 2,500 \\
\hline $\begin{array}{l}\text { Total Fat } \\
\text { Sat Fat }\end{array}$ & $\begin{array}{l}\text { Less than } \\
\text { Less than }\end{array}$ & $\begin{array}{l}65 \mathrm{~g} \\
20 \mathrm{~g}\end{array}$ & $\begin{array}{l}80 \mathrm{~g} \\
25 \mathrm{~g}\end{array}$ \\
\hline Cholesterol & Less than & $300 \mathrm{mg}$ & $300 \mathrm{mg}$ \\
\hline $\begin{array}{l}\text { Sodium } \\
\text { Total Carbohydrate }\end{array}$ & Less than & $\begin{array}{l}2,400 \mathrm{mg} \\
300 \mathrm{~g}\end{array}$ & $\begin{array}{l}2,400 \mathrm{mg} \\
375 \mathrm{~g}\end{array}$ \\
\hline Dietary Fiber & & $25 \mathrm{~g}$ & $30 \mathrm{~g}$ \\
\hline
\end{tabular}

New Label

\begin{tabular}{|c|c|}
\hline \multicolumn{2}{|l|}{$\begin{array}{l}8 \text { servings per container } \\
\text { Serving size } \quad 2 / 3 \mathbf{c u}\end{array}$} \\
\hline \multicolumn{2}{|l|}{ Amount per serving } \\
\hline \multicolumn{2}{|c|}{$\%$ Daily Value* } \\
\hline Total Fat $8 \mathrm{~g}$ & $10 \%$ \\
\hline Saturated Fat $1 \mathrm{~g}$ & $5 \%$ \\
\hline \multicolumn{2}{|l|}{ Trans Fat Og } \\
\hline Cholesterol Omg & $\mathbf{0 \%}$ \\
\hline Sodium 160mg & $7 \%$ \\
\hline Total Carbohydrate $37 \mathrm{~g}$ & $13 \%$ \\
\hline Dietary Fiber $4 \mathrm{~g}$ & $14 \%$ \\
\hline \multicolumn{2}{|l|}{ Total Sugars $12 \mathrm{~g}$} \\
\hline Includes $10 \mathrm{~g}$ Added Sugars & $20 \%$ \\
\hline \multicolumn{2}{|l|}{ Protein 3g } \\
\hline Vitamin D 2mcg & $10 \%$ \\
\hline Calcium 260mg & $20 \%$ \\
\hline Iron 8mg & $45 \%$ \\
\hline Potassium 235mg & $6 \%$ \\
\hline $\begin{array}{l}\text { "The \% Daily Value (DV) tells you how much } \\
\text { a serving of food contributes to a daily diet. } \\
\text { a day is used for general nutrition advice. }\end{array}$ & $\begin{array}{l}\text { trient in } \\
\text { calories }\end{array}$ \\
\hline
\end{tabular}

Source: Food and Drug Administration (n.d.) (Retrieved from https://www.fda.gov/media/97999/download)

\section{Obstacles from Food Industry}

Ultra-processed or ready-to-eat foods have become very popular items of consumption in modern life, and are a source of high sugar consumption. Martínez Steele et al. (2016) found that approximately 58\% of energy intake was from ultra-processed foods in the United States. These foods 
provided almost $90 \%$ of daily added-sugar intake. Several ultra-processed foods with added sugars were cakes, cookies, pies, soft drinks, fruit drinks, breakfast cereals, sweet snacks, ice creams and ice pops, milkbased drinks, and desserts. Furthermore, these sources of added sugar intake were not the main courses of daily meals. By comparing saturated fat, sugar, and sodium levels between the USDA sample menu and the same menu with ultra-processed food substitution, Tseng et al. (2018) found that the latter contained $274 \mathrm{kcal}$ less but $3.5 \%$ more sugar than the USDA's sample menu. Continuously consuming ultra-processed foods with relatively high sugar intake could cause health issues over the long run. It is obvious that manufacturers can produce more healthy foods with less added sugars; however, "sugar is cheap, sugar tastes good and sugar sells, so companies have little incentive to change" (Lustig, Schmidt and Brindis, 2012, p. 29). Not only do the manufacturers have poor motivation to lower added sugars in their products, but they also have some power to determine the display of added sugars on labels and packages.

As mentioned above, the FDA has given the manufacturers the right to determine which sugar-providing ingredients are added sugars and what formula should be used for amount calculation. Besides, the author's quick analysis of sugar names on the ingredient list provided on product packages indicates 20 easy-to-be-hidden sugar names. Obviously, the role of FDA in protecting consumers is questionable. Redmond (2009) questioned the regulatory role of FDA in allowing marketers to mislead consumers when it was established for the purpose of regulating markets and promoting public or consumer interests. Redmond also indicated two important problems in the food industry. First, food firms prioritize competitiveness and profitability above consumer sovereignty. Secondly, marketing research in the food industry allows firms to not only understand consumers' wants and needs but also to mislead consumers due to consumers' lack of ability to handle and process information within the time constraints of their daily lives. These strengthen the obstacles that created by the food industry.

\section{Obstacles Created by Marketing to Children}

Marketing that targets children creates additional problems. Herrick et al.'s (2020) research on added sugars indicated that in the US, "no national guidance on added sugar exists for infants and toddlers" (p. 23). Their data show that during 2011-2016 period, more than $60 \%$ of infants and $98 \%$ of toddlers consumed added sugars, primarily in foods such as yogurt, sweet bakery products, baby snacks, and fruit drinks. Although sugar consumption in infants and toddlers showed signs of decreasing 
between 2005 and 2016, this data indicates two problems. First, the authors observed that the decrease of sugar consumption in the very young did slow down in the later years, meaning this age group continues to consume added sugars. Second, infants should avoid any added sugar intake (Vos et al. 2017).

The US governmental policies regarding the use of brand mascots and media characters in marketing to children were unclear from 2006 to 2015. (Kraak and Story 2015a). Kraak and Story (2015b) further concluded that children prefer energy-dense and nutrient-poor foods over healthy food if branded by a familiar media character such as Dora or SpongeBob SquarePants. Vaala and Ritter's (2020) assessment of childoriented marketing of ready-to-eat cereals produced by companies that pledged to follow guidelines in promoting foods to children below 12 years old shows that:

Even companies that pledge to promote only relatively healthy cereals to children display a variety of child-oriented features on boxes of ready-to-eat cereals containing high amounts of sugar per ounce... Many cereals classified as moderate-sugar based on grams per serving are classified as high-sugar based on sugar per ounce. This mismatch suggested that many parents may be misled by the sugar content contained in the nutrition panel or many readyto-eat cereal boxes, potentially leading to a higher sugar intake among children than intended" (p. 219).

Their findings reinforce previous findings (Lapierre et al. 2017; Kraak and Story 2015b) concerning the linkage between high sugar content and children-oriented marketing.

With little attention from policymakers and high attention from industry, young consumers become an open target for different types of marketing. Such practices toward children expose them to foods with high added sugars and create large obstacles for parents who wish to lower the amount of added sugars in their children's meals. Obviously, infants, toddlers, and children are vulnerable consumers whose consumption is dependent on their parents. It would be easy to point the finger at parents, since they are responsible for their children's wellbeing; but parents are also subject to the obfuscation created by industry. As Gearhardt, Roberts and Ashe (2013) point out, the role of marketing in promoting foods with high added sugars is undeniable. Knowing the long-term consequences of high added sugars to the wellbeing of consumers is important for marketing, consumer behavior and other researchers who want to get involved in studying these issues to and protecting consumers. 


\section{Obstacles from the Influence of Sugar-Food Industries on Policymakers and Policy Influencers}

The obstacles created by the food industry reveal the relationship between the industry and the FDA. Redmond (2009) suggested that "in the case of food marketing, members of the internal and external polities, including food firms, industry lobbyists, administration officials, and elected representatives attempt to influence the FDA in its rule-making capacity" (p. 140). This suggestion implies that the relationship between policymakers-influencers and the food industry can be very complicated. It grants power to the industry to exploit consumers. As noted above, Kearns, Schmidt and Glantz (2016) conducted a historical analysis of internal industry documents regarding the SRF's sponsorship of sugar research. The analysis revealed that the coronary heart disease (CHD) research, which was sponsored by the SRF in 1965 and published in 1967 in the New England Journal of Medicine, was for the purpose of protecting the market. The research suggested a limited association between table sugar and CHD and there was no declaration of the SRF's funding of $\$ 48,900$ to Harvard scientists. Kearns. Schmidt and Glantz also indicated the sugar industry kept influencing other institutions such as the National Institute of Dental Research's National Caries Program in 1971 and the FDA in 1976 with the intent to alter the truth about sugar.

The sugar industry was not the only party, however, sponsoring research at health-related institutions. Aaron and Siegel (2017) showed that there were 95 national health organizations (including 63 public health organizations, 18 medical organizations, 7 health foundations, 5 government organizations, and 2 food supply groups) that received sponsorship from Coca-Cola Company and PepsiCo.

A total of 12 organizations accepted money from both companies (13\%), one accepted money from just PepsiCo (1\%), and 82 accepted money from the Coca-Cola Company only (86\%). Interestingly, whereas PepsiCo sponsored $14 \%$ of these health organizations, the Coca-Cola Company sponsored 99\%. However, this discrepancy may be an artifact due to Coca-Cola's recent disclosure of its sponsorships (Aaron and Siegel, 2017, p. 21).

Arron and Siegel also found that these two soft drink companies directly or indirectly lobbied for a total of 29 public health bills or proposed regulations in relation to taxes, food programs, advertising, product size limit, and labels from 2011 to 2015. Aaron and Siegel highlighted that among those bills, there was six federal bills, fourteen state bills, and nine local bills. They noted that two of these six federal legislations were about 
marketing to children. Their findings were from only two giant corporations in the beverage industry and the collected data were limited due to data tracking difficulty and companies' control on information disclosure.

The scientific evidence provided by Kearns, Schmidt and Glantz (2016) and Aaron and Siegel (2017) showed that the obstacles from policymaker-influencers to consumer wellbeing can come from two directions. First, policymakers and policy influencers seem to have a tacit agreement allowing them to be influenced by the corporations in the industries they regulate. Secondly, to protect the industry interests, the industries sought agreements with policymakers and policy influencers in order to gain more power and make it more difficult to provide the information necessary for consumers to lower their sugar consumption. It is difficult to estimate how deeply the sugar and food industries can influence policymakers and influencers. The findings of Kearns, Schmidt and Glantz (2016) and Aaron and Siegel (2017) indicate that the industries can influence consumers' wellbeing by lobbying policymakers and regulators to the industries' advantage. The current policies make it difficult for consumers to see the harm of sugar and thereby provide no reasons for lowering their sugar consumption. The handshake between industries, policymakers, and policy influencers places consumers in a very vulnerable position.

Redmond (2009), who noted the regulatory failure in the US packaged food markets, showed the relationship between food marketers and the FDA. The regulatory failure of government agencies such as the FDA, "did not happen by accident and is not the result of ineptness by lowlevel bureaucrats or staff scientists" (Redmond, 2009, p. 141). Such regulatory failure is related to information asymmetry, meaning consumers have less information in comparison with companies (Harris and Carman 1983). The information asymmetry creates superior power for firms who can then take advantage of their consumers. According to Redmond (2009):

Regulatory failure may be viewed as resulting from a combination of food firms' strategic interests in shaping the control system and the openness of the regulatory process to such influence (p. 141).

Created as an institution that regulates firms' practices in the market and protects consumers, during more than a hundred years of the FDA existence, the organization still needs to work harder in improving its regulatory system for protecting the consumers. 


\section{Obstacles Arising from Consumer Habits}

Ogden et al. (2014) reviewed obesity in the U.S, during 1999-2010 and estimated that obesity happened to approximately one-third of US adults and $17 \%$ of children. The data remained consistent between 2003-2004 and 2011-2012. Added sugar intake, obesity, and consumer' health are deeply related. To lower this rate of obesity in adults and children, it is important to break the habit of added sugar consumption. Changing this habit, however, has proven to be difficult and challenging for consumers. Mowen (1988) proposed three perspectives on viewing consumers' purchasing decision-making. The traditional decision-making perspective focuses on the rational information-processing approach; the experiential perspective focuses on consumers' sensory perception; and the behavioral influence perspective focuses on the influence from environment on behaviors of consumers. All three perspectives start with problem recognition. If giving up sugar is a decision-making event, it means that before the decision happens, consumers must recognize a problem in their sugar consumption. Without the awareness of the existence of the problem, there is no decision-making and no change occurs. Even when consumers are aware of the problem, according to Haws, Reczek and Sample (2017), they tend to overgeneralize that healthy foods cost more. This intuition influences consumer decision making. When consumers have limited product information or are unable to use prior knowledge to interpret a health claim, they tend to rely on their intuition that healthy foods are expensive. This intuition hinders consumers from making better consumption choices. The challenge for concerned marketing scholars, and for other concerned researchers, is how to help consumers recognize their problem with sugar consumption, given that the corporations that grow and process sugar and manufacture sugary foods have a very high influence in setting policies that maximize profits. The challenge is also to lessen the influence of the industry on the policymakers-influencers so that scholars can help cconsumers recognize the problem. When health-related information is difficult to find and to understand by some consumers, it is imperative to help consumers find quality information and give them the ability to make better decisions in purchasing and consuming high added-sugar food products. These are challenges for consumers and policymakers-influencers who care about consumers' wellbeing.

While sugar is an addiction (Avena, Rada and Hoebel 2008; Cantley 2014), it is different from other addictive substances such as alcohol and tobacco because sugar is also a nutrient (Lustig, Schmidt and Brindis 2012). Therefore, giving up something that tastes good and 
provides pleasure might be difficult for many people. With the entrenched habit of consuming added sugars that account for more than $10 \%$ of daily energy intakes, both normal-weight and obese consumers found the value of such foods was reinforced after they were placed on a healthy diet (less than $10 \%$ of kcal from total sugar) for a week (Flack et al. 2019). Moreover, Tryon et al. (2015) found that table sugar consumption is associated with cortisol reactivity to stress. This may make people who are under stress consume more sugar, therefore making it more difficult to give up. Consumers might find artificial sweeteners that are either no calorie or low-calorie as alternatives for sugar in their consumption. Using artificial sweeteners as a substitute for sugar, however, is often problematic (Cantley 2014). As Cantley explains, the intake of artificial sweeteners is very similar to fructose and sucrose intake. It creates a 'disconnect' between the actual amount of glucose intake and the amount of sweetness that the brain believes has been consumed. Thus, the brain drives consumers to eat more sweet foods in order to get enough glucose. Both artificial and natural sweeteners can exacerbate the addictive properties of sweet foods. The overcoming of this mental obstacle requires a lot of consumers' efforts and determination.

\section{Discussion and Suggested Solutions}

To overview, the obstacles that make it difficult for consumers to eat less sugar comes from policymakers, policy influencers, the sugar and food industries, as well as consumers themselves. Just as the obstacles to lowering the consumption of added sugars is the result of activities from many parties, any effective means of lowering consumption requires the effort of many disparate parties.

Lustig, Schmidt and Brindis (2012) suggest applying control strategies from supply side (as it is applied for both alcohol and tobacco) or limiting the sales time and purchase age limits can be interventions to protect consumers from sugar overconsumption. One such strategy has been to tax added sugar foods. Marinello et al. (2020) investigated the impact of beverage taxes on sugary drink prices in fast-food restaurants. Their findings from comparing before and after the application of a beverage tax indicated that only regular the consumption and sales of bottled soda were shown to be significantly different after one year. The results were insignificant for untaxed diet soda and fountain drinks. The additional taxes had little impact because the restaurants priced taxed and non-taxed beverages the same in order to simplify the menu. Besides, the estimated increase of $8 \%$ in prices was not high enough to make a significant difference in consumption habits. 
Some other suggestions from Lustig, Schmidt and Brindis (2012) were to remove high added-sugar products from the food stamp program or to scratch out fructose from the FDA's "Generally Regarded as Safe" list. Given the influence of industry contributions to politicians' campaigns and corporate presence in policymaking government bodies, however, federal policymakers are not very responsive to change. According to Lustig, Schmidt and Brindis, the United States Department of Agriculture (USDA) rejected the New York City petition to remove soft drinks from the food stamp program. Also, as discussed above, the FDA's guidance and changes in labels are not very effective. Probably, involvement from other parties such as consumer advocacy groups (Redmond 2009) in society are crucial for fueling these changes. Redmond, however, also pointed out that "low levels of financial and political resources of advocacy groups, combined with limited political efforts by consumers, result in an asymmetry of power and influence between consumer interests and food firm interests" (2009, p. 139). For these groups to be more active, their financial and political resources should be increased. Kraak and Story (2015a) suggested that the involvement of government, industry, civil society groups and the public are needed to publish better policies concerning brand mascot and media character usage in marketing practices. Hopefully, the involvement of these different entities will bring about greater accountability by the sugar industry and provide a healthy food environment to not only children in the specific context of this research but also other consumers in general.

Martínez Steele et al. (2016) also suggest that a reduction in the overall consumption of ultra-processed food might be a solution for reducing the added sugar intake of the U.S. consumers. As mentioned above, however, reduction of sugar consumption can reinforce the value of high sugar foods (Flack et al. 2019). Regarding this issue, Cantley (2014) concluded that "the only way really to prevent this problem - to break the addiction - is to go completely cold turkey and go off all sweeteners - artificial as well as fructose. Eventually the brain resets itself and you don't crave it as much" (pp. 3-4). This complete shutdown requires further research because there is limited understanding about how the value reinforcement of high added sugar foods happens in a long term (Flack et al. 2019) or with different types of sugars.

Arens and Hamilton (2016) suggested that when consumers pay attention to the differences between a healthy substitute and an unavailable unhealthy product in dieting, it helps them to reduce their desire of the unhealthy product more than when they focus on the similarities. This finding should not be applied, however, to sugar 
consumption due to the obstacles presented by having so many names for sugar. Consumers might consider honey, fruit juice or agave nectar as alternatives for sugar when they are indeed sugar. Even when consumers consider artificial sweeteners as alternatives for sugar, it still can induce addiction (Cantley 2014).

As addressed above, lifting these obstacles requires consumers' efforts and determination, which can be boosted by using a fresh start mindset. Price et al. (2018) defined a fresh start mindset as "a belief that people can make a new start, get a new beginning, and chart a new course in life, regardless of past or present circumstances" (p.22). This mindset can help consumers to adapt to changes or new circumstances as a way of self-enhancement. Documented by Price at al., this mindset is "positively associated with consumer variety seeking; self-focused transformative activities toward improving health, budget, personal relationships, and consumption practices" (2018, p.40). The fresh start mindset can be a psychological booster to motivate consumers to make changes.

The obstacles that inhibit consumers' wellbeing do not happen only in sugar consumption or food markets. They can also be found across other markets, where there is an intervention from firms - to influence regulatory agencies, such as the medical, insurance and real estate industries. Regarding the relationship between such industries and policymakers, Redmond (2009) noted that "the FDA receives input from firms, trade associations, and consumer advocacy groups, as well as from political sources including the executive branch and the legislative branch. Thus, the FDA is affected by lobbying efforts of the food industry, both directly on the FDA and indirectly through Congress" (p. 139). Expecting changes from industries or from the failure in their relationship with policymaker-influencers can be unrealistic because - as Redmond concluded - it requires transparency in transformation from informal norms to formal regulations. It also requires a balance between the rights for protecting corporate interests and the rights to protect consumer interests. Corporations are loathe to give up their interests; however, "the principle of consumer sovereignty may constitute a reasonable basis for limiting the political rights of firms to influence regulations. Upholding of consumer sovereignty as a fundamental goal in markets implies that marketers should not have the political right to manipulate control systems in ways that are incompatible with consumer interests" (Redmond 2009, p.143). It is also possible that consumer advocacy groups can make changes if the power of these groups is boosted appropriately. These 
groups act for the consumer interests and facilitate the change by influencing social media as well as regulators.

To conclude, this paper used findings about the negative influence of high added-sugar intake from different research fields - and especially fields that study nutrition, medical biology, and behavioral change - to analyze several obstacles preventing consumers from lowering their sugar consumption. The study, however, excludes the influence of excessive nocalorie or low-calories sweetener intake, which is also important to understand because of its strong relationship with sugar. Indeed, additional research is needed on the role of alternative sweeteners in consumer consumption behaviors, the role of the sweetener manufacturers in the sugar industry, and how the sweeteners affect consumers.

This paper also revealed a research gap about sugar consumption in marketing literature. There is limited understanding about how consumers perceive, feel, or think about sugar, or what role sugar plays in consumers' life. This paper explored only one dimension of the overall understanding of consumers' struggles in making healthy eating choices. The differences in sugar consumption across various cultures, different types of economies and societies, and across genders also remain as questions worth exploring. Indeed, there, at the global-societal level, there is a need to extend the work of Mintz to arenas beyond the Americas. The answers to multiple research questions from multiple disciplines are essential for researchers in figuring out solutions to help improve consumers' nutritional wellbeing. 


\section{References}

Aaron, Daniel G. and Michael B. Siegel (2017), "Sponsorship of National Health Organizations by Two Major Soda Companies," American Journal of Preventive Medicine, 52 (1), 20-30. https://doi.org/10.1016/j.amepre.2016.08.010

American Heart Association (2018), "Added Sugar," (accessed on Oct 31, 2020), [available at: https://www.heart.org/en/healthy-living/healthyeating/eat-smart/sugar/added-sugars]

Arens, Zachary G. and Rebecca W. Hamilton (2016), "Why Focusing on the Similarity of Substitutes Leaves a lot to be Desired," Journal of Consumer Research, 43 (3), 448-59. https://doi.org/10.1093/jcr/ucw034

Avena, Nicole M., Pedro Rada and Bartley G. Hoebel (2008), "Evidence for Sugar Addiction: Behavioral and Neurochemical Effects of Intermittent, Excessive Sugar Intake," Neuroscience and Biobehavioral Reviews, 32 (1), 20-39. https://doi.org/10.1016/j.neubiorev.2007.04.019

Breslin, Paul AS. (2013), "An Evolutionary Perspective on Food and Human Taste," Current Biology, 23 (9), R409-18. https://doi.org/10.1016/j.cub.2013.04.010

Burt, Brian A. and Satishchandra Pai (2001), "Sugar Consumption and Caries Risk: A Systematic Review," Journal of dental education, 65 (10), 1017-23. $\quad$ https://doi.org/10.1002/j.00220337.2001.65.10.tb03444.x

Cantley, Lewis C. (2014), "Cancer, Metabolism, Fructose, Artificial Sweeteners, and Going Cold Turkey on Sugar," BMC Biology, 12 (1), 1-4. https://doi.org/10.1186/1741-7007-12-8

Derby, Brenda M. and Alan S. Levy (2001), "Do Food Labels Work: Gauging the Effectiveness of Food Labels pre-and post-NLEA," In Handbook of Marketing and Society, Paul N. Bloom and Greg T. Gundlach, eds. Thousand Oaks, CA: Sage, 372-98.

Docherty, Neil (Producer/Director), Allya Davidson and Ronna Syed (Associate Producers) (2013), "The Secrets of Sugar," The fifth estate, CBS News, October 4, (accessed on October 31, 2020), [available at: https://www.cbc.ca/fifth/episodes/2013-2014/thesecrets-of-sugar] 
Flack, Kyle D., Kelsey Ufholz, Shanon Casperson, Lisa Jahns, LuAnn Johnson and James Roemmich (2019), "Decreasing the Consumption of Foods with Sugar Increases Their Reinforcing Value: A Potential Barrier for Dietary Behavior Change," Journal of the Academy of Nutrition and Dietetics, 119 (7), 1099-108. https://doi.org/10.1016/j.jand.2018.12.016

Food and Drug Administration (2018, revised 2019), "Nutrition and Supplement Facts Labels: Questions and Answers Related to the Compliance Date, Added Sugars, and Declaration of Quantitative Amounts of Vitamins and Minerals: Guidance for Industry," (accessed on October 31, 2020), [available at: https://www.fda.gov/media/117402/download

Food and Drug Administration (n.d.), "Changes to the Nutrition Facts Label," (accessed on October 31, 2020), [available at: https://www.fda.gov/food/food-labeling-nutrition/changes-nutritionfacts-label]

Food and Drug Administration (n.d.), "Side-by-side Comparison," (accessed on October 31, 2020), [available at: https://www.fda.gov/media/97999/download]

Gearhardt, Ashley, Michael Roberts and Marice Ashe (2013), "If Sugar Is Addictive... What Does It Mean for the Law?" Journal of Law, Medicine \& Ethics, 41 (1_suppl), 46-49. https://doi.org/10.1111/jlme.12038

Goncalves, Marcus D., Benjamin D. Hopkins and Lewis C. Cantley (2019), "Dietary Fat and Sugar in Promoting Cancer Development and Progression," Annual Review of Cancer Biology, 3 (1), 255-73. https://doi.org/10.1146/annurev-cancerbio-030518-055855

Harris, Robert G. and James M. Carman (1983), "Public Regulation of Marketing Activity: Part I: Institutional Typologies of Market Failure," Journal of Macromarketing, $3 \quad$ (1), 49-58. https://doi.org/10.1177\%2F027614678300300108

Haws, Kelly L., Rebecca Walker Reczek and Kevin L. Sample (2017), "Healthy Diets Make Empty Wallets: The Healthy= Expensive Intuition," Journal of Consumer Research, 43 (6), 992-1007. https://doi.org/10.1093/jcr/ucw078

Herrick, Kirsten A., Cheryl D. Fryar, Heather C. Hamner, Sohyum Park and Cynthia L. Ogden (2020), "Added Sugars Intake among US 
Infants and Toddlers," Journal of the Academy of Nutrition and Dietetics, 120 (1), 23-32. https://doi.org/10.1016/j.jand.2019.09.007

Imamura, Fumiaki, Laura O'Connor, Zheng Ye, Jaakko Mursu, Yasuaki Hayashino, Shilpa N. Bhupathiraju and Nita G. Forouhi (2016), "Consumption of Sugar Sweetened Beverages, Artificially Sweetened Beverages, and Fruit Juice and Incidence of Type 2 Diabetes: Systematic Review, Meta-analysis, and Estimation of Population Attributable Fraction," British Journal of Sports Medicine, 50 (8), 496-504. https://doi.org/10.1136/bjsports-2016h3576rep

Kraak, Vivica I. and Mary Story (2015a), "An Accountability Evaluation for the Industry's Responsible Use of Brand Mascots and Licensed Media Characters to Market a Healthy Diet to American Children," Obesity Reviews, 16 (6), 433-53. https://doi.org/10.1111/obr.12279

Kraak, Vivica I., and Mary Story (2015b), "Influence of Food Companies' Brand Mascots and Entertainment Companies' Cartoon Media Characters on Children's Diet and Health: A Systematic Review and Research Needs." Obesity Reviews, 16 (2), 107-26. https://doi.org/10.1111/obr.12237

Kearns, Cristin E., Laura A. Schmidt and Stanton A. Glantz (2016), "Sugar Industry and Coronary Heart Disease Research: A Historical Analysis of Internal Industry Documents," JAMA Internal Medicine, 176 https://doi.org/10.1001/jamainternmed.2016.5394

1680-85.

Lapierre Matthew A., Autumn M Brown, Hunter V Houtzer and Tyler J. Thomas (2017), "Child-directed and Nutrition-focused Marketing Cues on Food Packaging: Links to Nutritional Content," Public health nutrition, $20 \quad$ (5), $465-73$. https://doi.org/10.1017/S1368980016002317

Lauby-Secretan, Béatrice, Chiara Scoccianti, Dana Loomis, Yann Grosse, Franca Bianchini, Kurt Straif, (2016). Body Fatness and Cancer-Viewpoint of the IARC Working Group. The New England Journal of Medicine, 375 https://doi.org/10.1056/NEJMsr1606602

(8), 794-798.

Lustig, Robert H., Laura A. Schmidt and Claire D. Brindis (2012), "The Toxic Truth about Sugar," Nature, 482 (7383), 27-29. https://doi.org/10.1038/482027a 
Malik, Vasanti S., Barry M. Popkin, George A. Bray, Jean-Pierre Després and Frank B. Hu (2010), "Sugar-Sweetened Beverages, Obesity, Type 2 Diabetes Mellitus, and Cardiovascular Disease Risk," Circulation, $121 \quad$ (11), $1356-64$. https://doi.org/10.1161/CIRCULATIONAHA.109.876185

Marinello, Samantha, Andrea A. Pipito, Julien Leider, Oksana Pugach and Lisa M. Powell (2020), "The Impact of the Oakland SugarSweetened Beverage Tax on Bottled Soda and Fountain Drink Prices in Fast-food Restaurants." Preventive Medicine Reports, 17, 101034. https://doi.org/10.1016/j.pmedr.2019.101034

Martínez Steele, Eurídice, Larissa G. Baraldi, Maria L. C. Louzada, JeanClaude Moubarac, Dariush Mozaffarian and Carlos A. Monteiro (2016), "Ultra-processed Foods and Added Sugars in the US Diet: Evidence from a Nationally Representative Cross-sectional Study," BMJ Open, 6 (3), 009892. https://doi.org/10.1136/bmjopen-2015$\underline{009892}$

Mintz, Sidney Wilfred (1986), Sweetness and power: The place of sugar in modern history. New York: Penguin.

Mowen, John C. (1988), "Beyond Consumer Decision Making," Journal of Consumer Marketing, 5 (1), 1525. https://doi.org/10.1108/eb008214

Neuhofer, Zachary, Brandon R. Mcfadden, Alicia Rihn, Xuan Wei, Hayk Khachatryan and Lisa House (2020), "Can the Updated Nutrition Facts Label Decrease Sugar-sweetened Beverage Consumption?" Economics and Human Biology, 37, 100867. https://doi.org/10.1016/j.ehb.2020.100867

Ogden, Cynthia L., Margaret D. Carroll, Brian K. Kit and Katherine M. Flegal (2014), "Prevalence of Childhood and Adult Obesity in the United States, 2011-2012," JAMA, 311 (8), 806-14. https://doi.org/10.1001/jama.2014.732

Peres, Marco, Aubrey Sheiham, Pingzhou Liu, Flavio F. Demarco, Alexander E. R. Silva, Maria C. Assunção, Ana M. Menezes, Fernando C. Barros and Karen G. Peres (2016), "Sugar Consumption and Changes in Dental Caries from Childhood to Adolescence," Journal of Dental Research, 95 (4), 388-94. https://doi.org/10.1177/0022034515625907

Price, Linda L., Robin A. Coulter, Yuliya Strizhakova and Ainslie N. Schultz (2018), "The Fresh Start Mindset: Transforming 
Consumers' Lives," Journal Of Consumer Research, 45 (1), 21-48. https://doi.org/10.1093/jcr/ucx115

Redmond, William H. (2009), "A Political Economy of Regulatory Failure in US Packaged Food Markets," Journal of Macromarketing, 29 (2), 135-44. https://doi.org/10.1177/0276146708327631

Reis, Daniel J., Stephen S. Ilardi, Michael S. Namekata, Erik K. Wing and Carina H. Fowler (2020), "The Depressogenic Potential of Added Dietary Sugars," Medical Hypotheses, 134, 109421. https://doi.org/10.1016/j.mehy.2019.109421

SugarScience. (n.d.) "Hidden in Plain Sight," (accessed on Oct 31, 2020), [available at: https://sugarscience.ucsf.edu/hidden-in-plainsight/\#.Xk4bbWhKhPZ]

The Sugar Association (n.d.), "Sugar vs. Sugars," (accessed on Oct 31, 2020), [available at: https://www.sugar.org/sugar/sugars/]

Tryon, Matthew S., Kimer L. Stanhope, Elissa S. Epel, Ashley E. Mason, Rashida Brown, Valentina Medici, Peter J. Havel and Kenvin D. Laugero. (2015), "Excessive Sugar Consumption May Be a Difficult Habit to Break: A View from the Brain and Body," The Journal of Clinical Endocrinology \& Metabolism, 100 (6), 2239-47. https://doi.org/10.1210/jc.2014-4353

Tseng, Marilyn, Dawn B. Neill, Stephanie F. Teaford and Aydin Nazmi (2018), "Alternative MyPlate Menus: Effects of Ultra-Processed Foods on Saturated Fat, Sugar, and Sodium Content," Journal of Nutrition Education and Behavior, 50 (3), 258-66. https://doi.org/10.1016/j.jneb.2017.10.009

Vaala, Sarah E. and Matthew B. Ritter (2020), "Child-Oriented Marketing on Cereal Packaging: Associations with Sugar Content and Manufacturer Pledge," Journal of Nutrition Education and Behavior, 52 (3), 215-23. https://doi.org/10.1016/i.jneb.2020.01.005

Vos, Miriam B., Jill L. Kaar, Jean A. Welsh, Linda V. Van Horn, Daniel I. Feig, Cheryl A.M. Anderson, Mahesh J. Patel, Jessica Cruz Munos, Nancy F. Krebs, Stavra A. Xanthakos and Rachel K. Johnson (2017), "Added Sugars and Cardiovascular Disease Risk in Children: A Scientific Statement From the American Heart Association," Circulation, 135 (19), e1017-34. https://doi.org/10.1161/CIR.0000000000000439 
World Health Organization (2015), "Guideline: Sugars intake for adults and children," World Health Organization, (accessed on Oct 31, 2020), [available

https://www.who.int/publications/i/item/9789241549028]

Yang, Quanhe, Zefeng Zhang, Edward W. Gregg, Dana Flanders, Robert Merritt and Frank B. Hu (2014), "Added Sugar Intake and Cardiovascular Diseases Mortality among US Adults," JAMA Internal Medicine, $174 \quad$ (4), 516-24. https://doi.org/10.1001/jamainternmed.2013.13563

Yu, Ching-Jung, Jung-Chieh Du, Hsien-Chih Chiou, Chun-Cheng Feng, Ming-Yi Chung, Winnie Yang, Ying-Sheue Chen, Ling-Chu Chien, Betau Hwang and Mei-Lien Chen (2016), "Sugar-Sweetened Beverage Consumption Is Adversely Associated with Childhood Attention Deficit/Hyperactivity Disorder," International Journal of Environmental Research and Public Health, 13 (7), 678. https://doi.org/10.3390/ijerph13070678 